\title{
Helicobacter acinonyx sp. nov., Isolated from Cheetahs with Gastritis
}

\author{
K. A. EATON, ${ }^{1 *}$ F. E. DEWHIRST, ${ }^{2}$ M. J. RADIN, ${ }^{1}$ J. G. FOX,${ }^{3}$ B. J. PASTER,${ }^{2}$ \\ S. KRAKOWKA, ${ }^{1}$ AND D. R. MORGAN ${ }^{4}$ \\ Department of Veterinary Pathobiology, Ohio State University, 1925 Coffey Road, \\ Columbus, Ohio 43210 ${ }^{1}$; Forsyth Dental Center, Boston, Massachusetts $02115^{2}$; \\ Division of Comparative Medicine, Massachusetts Institute of Technology, \\ Cambridge, Massachusetts 021393; and The Procter and Gamble Co.,
} Cincinnati, Ohio $45339^{4}$

\begin{abstract}
Four strains of a novel Helicobacter species were isolated from the stomachs of cheetahs (Acinonyx jubilatus) with gastritis. These isolates were phenotypically similar to Helicobacter pylori. The isolates were gram-negative, spiral bacteria which grew under microaerophilic conditions at $37^{\circ} \mathrm{C}$, but not at 25 or $42^{\circ} \mathrm{C}$, and produced urease, catalase, oxidase, alkaline phosphatase, and gamma-glutamyl transpeptidase. The isolates did not ferment glucose, mannitol, inositol, sorbitol, rhamnose, sucrose, melibiose, amygdalin, or arabinose; hydrolyze hippurate or indoxyl acetate; or reduce nitrate. They did not produce $\mathrm{H}_{2} \mathrm{~S}$ from triple sugar iron agar, and they did not grow in the presence of $1.0 \%$ glycine or $1.5 \% \mathrm{NaCl}$. They were resistant to nalidixic acid and sensitive to cephalothin and metronidazole. Cells were typically $0.3 \mathrm{by} 2.0 \mu \mathrm{m}$ and possessed tufts of two to five sheathed, monopolar flagella. The $G+C$ content of strain 90-119 was 30 mol\%. Cluster analysis of densitometry scans of polyacrylamide protein gels revealed more than $70 \%$ similarity of the cheetah isolates to $\mathrm{H}$. pylori, less than $60 \%$ similarity to Helicobacter felis, and less than 50\% similarity to Helicobacter mustelae. Complete 16S rRNA sequences were determined for two of the cheetah isolates. Phylogenetic analysis was performed by comparing the cheetah sequences to those of 19 reference strains, including $H$. pylori, $H$. felis (two strains), $H$. mustelae, Helicobacter muridarum, "Flexispira rappini," Wolinella succinogenes, Campylobacter coli, Campylobacter concisus, Campylobacter curvus, Campylobacter fetus, Campylobacter hyointestinalis, Campylobacter jejuni, Campylobacter lari, Campylobacter rectus, Campylobacter sputorum subsp. bubulus, a Campylobacter sp. (pig isolate), [Bacteroides] gracilis, and [Bacteroides] ureolyticus. The 16S rRNA sequences for 13 of the 19 reference species have not previously been reported. Phylogenetic analysis demonstrated that the cheetah isolates were most closely related to $H$. pylori $(97.4 \%$ similarity), $H$. felis $(96.1 \%$ similarity), and $H$. mustelae $(93.4 \%$ similarity). On the basis of these findings, we propose that these isolates represents a novel species of Helicobacter, which we designate Helicobacter acinonyx. The type strain is 90-119 (CCUG 29263, ATCC 51101).
\end{abstract}

The genus Helicobacter currently comprises seven species: Helicobacter pylori $(25), H$. mustelae $(9-11,14,30), H$. felis $(21-23,30), H$. muridarum $(24), H$. cinaedi $(8,35,36)$, $H$. fennelliae $(8,35,36)$, and $H$. nemestrinae (2). Strains representing six additional Helicobacter species have been identified by rRNA-DNA hybridization (34) and 16S rRNA sequencing (5). These include three species isolated from bird feces (29); "Flexispira rappini," isolated from human and ovine sources $(1,4)$; CLO-3, isolated from humans $(8$, $35)$; $90-266-11$, a strain isolated from ferret feces that differs from $H$. mustelae (13); and CCUG 29176, a strain isolated from human blood. Many of the Helicobacter species cause chronic gastritis in their natural hosts: $H$. pylori in humans (25), $H$. mustelae in ferrets (11), and $H$. felis in dogs (23). $H$. felis also induces gastritis when inoculated into germfree mice and rats $(12,21)$, as does $H$. pylori when given per os to germfree piglets and dogs $(19,31)$. In this paper we describe a novel Helicobacter sp. based on four isolates from captive cheetahs with chronic gastritis. These isolates are biochemically and culturally similar to previously described Helicobacter species but are clearly differentiated from known Helicobacter species by sodium dodecyl sulfate (SDS)polyacrylamide gel electrophoresis protein profile, $\mathrm{G}+\mathrm{C}$ content, and $16 \mathrm{~S}$ rRNA sequence. We propose that the organism be named Helicobacter acinonyx.

\footnotetext{
* Corresponding author.
}

\section{MATERIALS AND METHODS}

Bacterial strains and culture conditions. The strain names, sources, and accession numbers for the organisms examined in this study are listed in Table 1. The isolation of Helicobacter species strains 90-119, 90-548, 90-736, and 90-1908 from gastric biopsies of four captive cheetahs (Acinonyx jubilatus) was previously described (6). Unless otherwise stated, all bacteria were grown on tryptic soy agar (BBL, Cockeysville, Md.) with $5 \%$ sheep blood (blood agar plates) and incubated for 3 days at $37^{\circ} \mathrm{C}$ in an atmosphere of $5 \% \mathrm{O}_{2}$, $10 \% \mathrm{CO}_{2}$, and $85 \% \mathrm{~N}_{2}$. Growth at 25 and $42^{\circ} \mathrm{C}$ was determined on blood agar plates under microaerophilic conditions. Aerobic and anaerobic growth was determined at $37^{\circ} \mathrm{C}$. Anaerobiosis was achieved with a GasPak jar and anaerobic generator envelope (BBL). Growth on $1.0 \%$ glycine and $1.5 \% \mathrm{NaCl}$ was determined with brucella agar (Difco Laboratories, Detroit, Mich.) containing 10\% fetal calf serum $(\mathrm{NaCl})$ or $10 \%$ sheep blood (glycine) and the appropriate additive. Antibiotic sensitivities were determined by using blood agar plates. The surfaces of the plates were inoculated with a swab which had been dipped in a heavy suspension of bacteria. Antibiotic discs were placed on the plates. Strains were considered sensitive if there was a zone of inhibition of $2 \mathrm{~cm}$ or more after 3 days of incubation. Antibiotics used were purchased from BBL except for metronidazole (Unipath, Columbia, Md.). The antibiotics used were cephalothin $(30 \mu \mathrm{g})$, nalidixic acid (30 
TABLE 1. Sources and accession numbers of strains studied

\begin{tabular}{|c|c|c|c|c|}
\hline Organism $^{a}$ & Strain $^{b}$ & Source $^{c}$ & Other source(s) and strain no. ${ }^{d}$ & GenBank no. ${ }^{e}$ \\
\hline Helicobacter acinonyx & $90-119$ & Eaton & CCUG $29263^{\mathrm{T}}$, ATCC 51101 & M88148f \\
\hline Helicobacter acinonyx & $90-548$ & Eaton & ATCC 51102 & \\
\hline Helicobacter acinonyx & $90-736$ & Eaton & ATCC 51103 & \\
\hline Helicobacter acinonyx & $90-1908$ & Eaton & ATCC 51104 & M88149f \\
\hline Helicobacter felis & $\mathrm{CS} 1$ & Lee & $\operatorname{ATCC} 49179^{\mathrm{T}}$ & M37642 \\
\hline Helicobacter felis & DS3 & Lee & & M37643 \\
\hline Helicobacter mustelae & R85-13-6P & Fox & ATCC $43772^{\mathrm{T}}$ & M35048 \\
\hline Helicobacter muridarum & ST1 & Lee & ATCC $49282^{\mathrm{T}}$, CCUG $29262^{\mathrm{T}}$ & M80205 \\
\hline Helicobacter pylori & $\operatorname{ATCC} 43504^{\mathrm{T}}$ & ATCC & & $\mathrm{M} 88157^{f}$ \\
\hline "Flexispira rappini" & NADC 1893 & Bryner & ATCC 43966 & $\mathrm{M} 88137^{f}$ \\
\hline "Flexispira rappini" & NADC 1937 & Bryner & ATCC 43879 , CCUG 23435 & M88138f \\
\hline Wolinella succinogenes & ATCC $29543^{\mathrm{T}}$ & ATCC & & M88159f \\
\hline Campylobacter coli & CCUG $11283^{\mathrm{T}}$ & CCUG & & $\mathrm{L} 04312^{f}$ \\
\hline Campylobacter concisus & FDC $484^{\mathrm{T}}$ & Tanner & ATCC $33237^{\mathrm{T}}$ & $\mathrm{L} 04322^{f}$ \\
\hline Campylobacter curvus & ATCC $35224^{\mathrm{T}}$ & ATCC & & $\mathrm{L} 04313^{f}$ \\
\hline Campylobacter fetus subsp. fetus & ATCC $27374^{\mathrm{T}}$ & ATCC & & M65012 \\
\hline Campylobacter hyointestinalis & ATCC $35217^{\mathrm{T}}$ & ATCC & & M65010 \\
\hline Campylobacter jejuni & CCUG 112844 & CCUG & & L04315 \\
\hline Campylobacter lari & CCUG $23947^{\mathrm{T}}$ & CCUG & & L04316 $f^{f}$ \\
\hline Campylobacter rectus & ATCC $33238^{\mathrm{T}}$ & ATCC & & L04317 \\
\hline Campylobacter species & $40-6 \mathrm{AT}$ & Morgan & & $\mathrm{L} 04318^{f}$ \\
\hline Campylobacter sputorum subsp. bubulus & ATCC 33491 & ATCC & & L04319f \\
\hline [Bacteroides] gracilis & ATCC $33236^{T}$ & ATCC & & $\mathrm{L} 04320^{f}$ \\
\hline [Bacteroides] ureolyticus & ATCC $33387^{\mathrm{T}}$ & ATCC & & $\mathrm{L} 04321^{f}$ \\
\hline
\end{tabular}

\footnotetext{
${ }^{a}$ Organisms are listed according to current nomenclature. Square brackets indicate that an organism does not belong in the genus indicated.

${ }^{b}$ Abbreviations for culture collections: ATCC, American Type Culture Collection; CCUG, Culture Collection, University of Göteborg; FDC, Forsyth Dental Center, Boston, Mass.; NADC, National Animal Disease Center, Ames, Iowa.

${ }^{c}$ Strains were obtained directly from the indicated culture collection (abbreviated as shown above) or from individuals, as follows: J. H. Bryner, National Animal Disease Center; K. Eaton, Department of Veterinary Pathobiology, Ohio State University, Columbus; J. G. Fox, Massachusetts Institute of Technology, Cambridge, Mass.; A. Lee, School of Microbiology and Immunology, University of New South Wales, Sydney, New South Wales, Australia; D. R. Morgan, The Procter and Gamble Co., Cincinnati, Ohio; and A. R. C. Tanner, Forsyth Dental Center.

${ }^{d}$ Culture collection sources for strains obtained from individuals. Culture collection abbreviations are as shown above.

e 16S rRNA sequences for these strains are available for electronic retrieval from GenBank under the indicated accession numbers. Through cross distribution of data bases, these sequences should also be available from European and Japanese data bases.

$f$ Sequence deposited with GenBank for this publication.
}

$\mu \mathrm{g})$, metronidazole $(5 \mu \mathrm{g})$, penicillin $(2 \mathrm{U})$, ampicillin (10 $\mu \mathrm{g})$, nitrofurazone $(100 \mu \mathrm{g})$, sulfamethoxazole $(33.75 \mu \mathrm{g})$ with trimethoprim $(1.25 \mu \mathrm{g})$, erythromycin $(15 \mu \mathrm{g})$, vancomycin $(30 \mu \mathrm{g})$, gentamicin $(10 \mu \mathrm{g})$, chlortetracycline $(30 \mu \mathrm{g})$, and chloramphenicol $(30 \mu \mathrm{g})$.

Electron microscopy. Cells were negatively stained with $1 \%$ phosphotungstic acid ( $\mathrm{pH} \mathrm{6.5)}$ for 15 to $20 \mathrm{~s}$. Specimens were examined with a Jeol JEM-1200EX transmission electron microscope operating at $100 \mathrm{kV}$.

Biochemical characterization. Bacteria were grown in brucella broth (Difco) with $10 \%$ fetal bovine serum. Bacteria were harvested by centrifugation, washed in phosphatebuffered saline, counted with a hemacytometer, and adjusted to $1.0 \times 10^{9}$ bacteria per $\mathrm{ml}$. Production of urease was determined by observing a color change upon inoculation of urea broth (BBL), production of catalase was determined by inoculation of $3 \% \mathrm{H}_{2} \mathrm{O}_{2}$ and looking for bubbles, and production of oxidase was determined by assessing the ability to oxidize $N, N, N^{\prime}, N^{\prime}$-tetramethyl-p-phenylenediamine dihydrochloride (Spottest; Difco). Monosaccharide fermentation, $\mathrm{H}_{2} \mathrm{~S}$ production, and nitrate reduction were tested with API 20E kits (Analytab, Plainview, N.Y.) according to the manufacturer's instructions (7). In addition, cultures were inoculated into triple sugar iron slants (BBL) and incubated overnight in $10 \% \mathrm{CO}_{2}$ at $37^{\circ} \mathrm{C}$. Aminopeptidases, alkaline phosphatase, acid phosphatase, and phosphohydrolase tests were performed with API ZYM (16) and An-IDENT $(16,37)$ kits (Analytab). Gamma-glutamyl transpeptidase was measured by adding $100 \mu \mathrm{l}$ of suspended bacteria $\left(1 \times 10^{9}\right.$ bacteria per $\mathrm{ml}$ ) to $100 \mu \mathrm{l}$ of $0.2 \%$ gamma-glutamyl-betanaphthylamide in $50 \mathrm{mM} \mathrm{N}$-tris(hydroxymethyl)methyl-2aminoethanesulfonic acid (TES) (pH 7.5) buffer in a 96-well microtiter plate. Following $4 \mathrm{~h}$ of incubation at $37^{\circ} \mathrm{C}$, the reaction was developed with 1 drop of Cinnamaldehyde Reagent (An-IDENT; Analytab Products). The indoxyl acetate hydrolysis test was performed by the disc method of Hodge et al. (15). Positive reactions were indicated by the appearance of a green or blue color within $20 \mathrm{~min}$. The hippurate hydrolysis test was performed by the method of Hwang and Ederer (17).

TABLE 2. Sequencing primers

\begin{tabular}{lll}
\hline Primer & Positions & \multicolumn{1}{c}{ Sequence $^{a}$} \\
\hline 1 & $159-175$ & 5'-GTATTAATCACCGTTTC-3' $^{\prime}$ \\
2 & $344-358$ & 5'-ACTGCTGCCTCCCGT-3' \\
3 & $519-536$ & 5'-GWATTACCGCGGCKGCTG-3' \\
4 & $786-803$ & 5'-CTACCAGGGTATCTAATC-3' \\
5 & $907-926$ & 5'-CCGTCAATTCMTTTRAGTTT-3' \\
6 & $951-964$ & 5'-TCGAATTAAACCAC-3' \\
7 & $962-985$ & 5'-GGTAAGGTTCTTCGYGTATCTTCG-3' \\
8 & $1096-1113$ & 5'-GGTTGCGCTCGTTGCGGG-3' \\
9 & $1392-1406$ & 5'-ACGGGCGGTGTGTR-3' \\
10 & $1493-1513$ & 5'-TACGGYTACCTTGTTACGACT-3'
\end{tabular}

${ }^{a}$ The sequences are complementary to $16 \mathrm{~S}$ rRNA at the positions listed $(E$. coli numbering system). Base codes are standard International Union of Biochemistry codes for bases and ambiguity. 

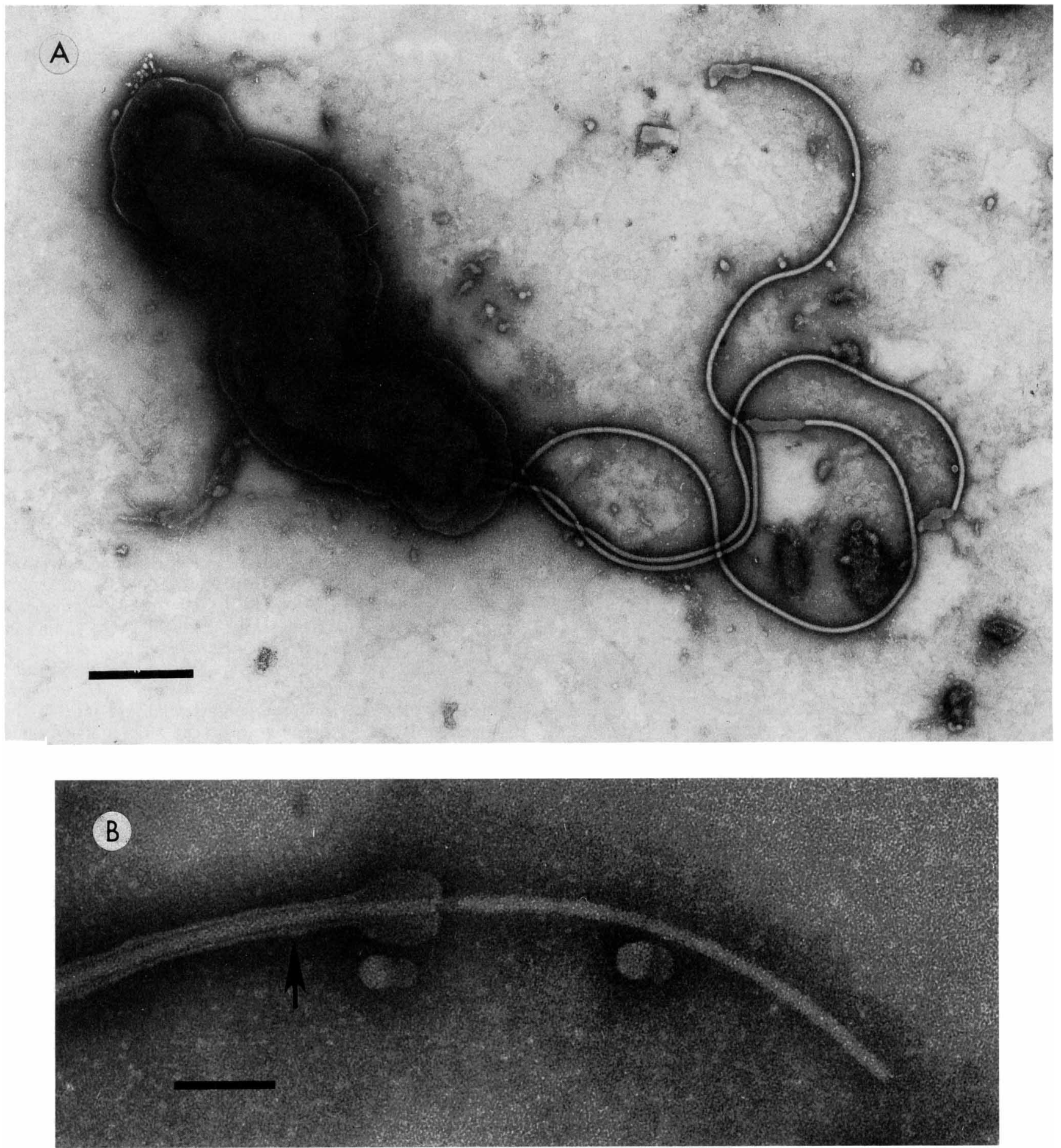

FIG. 1. (A) Electron micrograph of $H$. acinonyx showing short, spiral morphology and polar tuft of flagella. Bar $=0.5 \mu \mathrm{m}$. (B) Electron micrograph of flagellum of $H$. acinonyx showing flagellar sheath (arrow). Bar $=0.1 \mu \mathrm{m}$.

Protein profiles. Protein profiles for the cheetah isolates and reference strains were determined by Coomassie blue staining of proteins separated on SDS $-12 \%$ polyacrylamide gels (6). Densitometry scans of SDS gels were performed with an Ultroscan XL laser densitometer and analyzed with custom-designed software (26).

G $+\mathbf{C}$ content. The $\mathrm{G}+\mathrm{C}$ content of DNA was determined by thermal denaturation analysis as previously described (24). DNA isolated from Escherichia coli K-12 was used for control determinations.

16S rRNA sequencing. rRNAs were isolated and partially purified by a modification of the procedure of Pace et al. (27) as previously described (28). rRNA sequences were determined by using a modification of the standard Sanger 

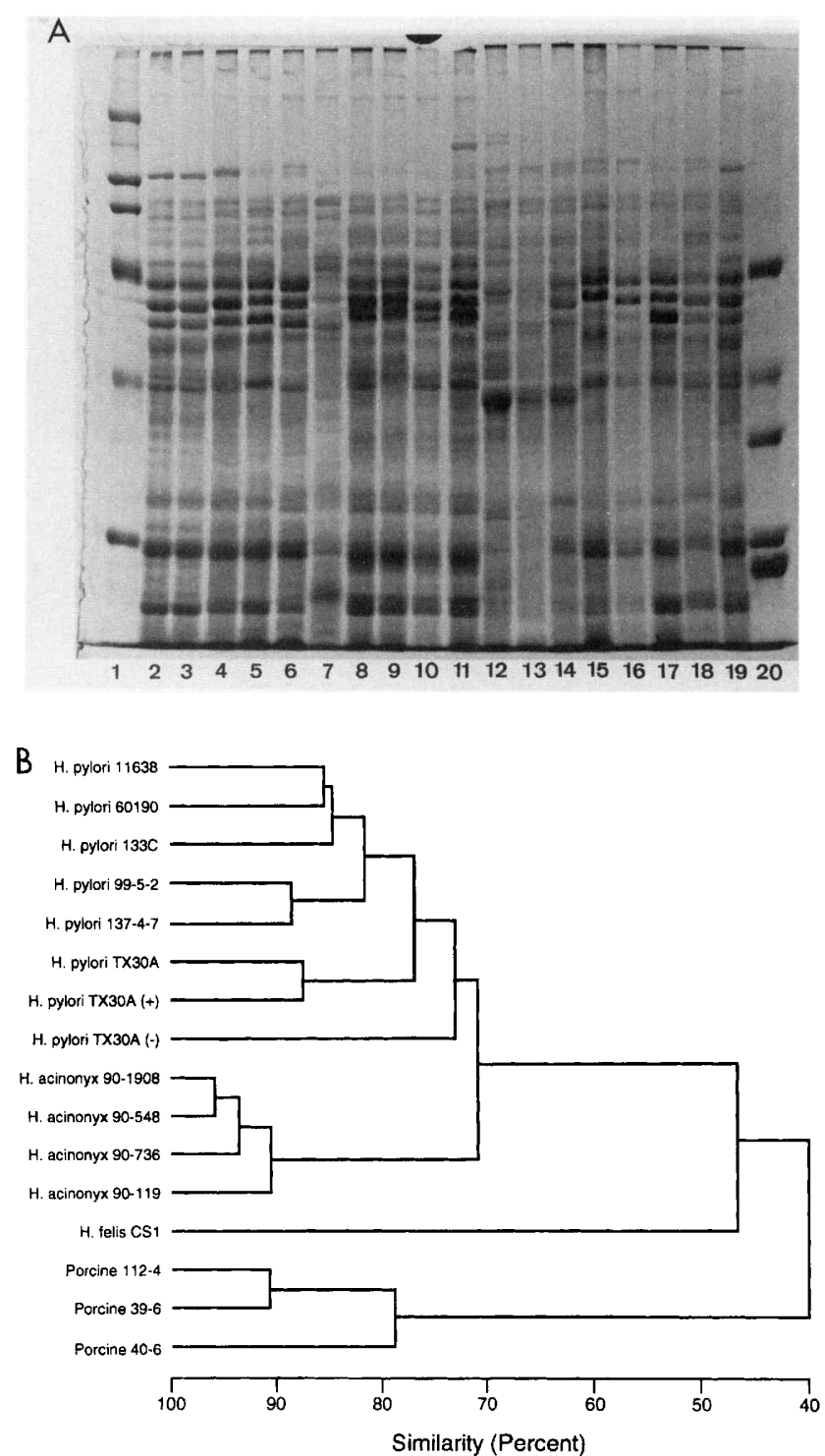

FIG. 2. (A) Polyacrylamide gel protein profile of $H$. acinonyx and related species. Lanes 1 and 20, protein size markers; lanes 2 through 6 and 15 through $19, \mathrm{H}$. pylori; lane 7, H. felis; lanes 8 through 11, $H$. acinonyx; lanes 12 through 14, porcine Campylobacter species strains. (B) Phylogenetic tree derived from cluster analysis of densitometry scans of the gel shown in panel A. Horizontal scale indicates percent similarity.

dideoxy chain termination technique (20). Primers complementary to conserved regions of the 16S rRNA sequence were elongated by using avian myeloblastosis virus reverse transcriptase (28). The eight primers used to obtain nearly complete sequences for $H$. acinony $x$ and reference species are given in Table 2 . For most of the species examined in this study, primers 2 through 6 and 8 through 10 were used. Primers 6 and 7 were used to obtain sequence information 5 to a hard stop at $E$. coli position 970 . Primer 6 was used in early sequencing studies and was subsequently replaced by primer 7. Primer 1 was used to obtain sequence information $5^{\prime}$ to a hard stop at $E$. coli position 210 in some Helicobacter species.

16S rRNA data analysis. A program set for data entry, editing, sequence alignment, secondary-structure comparison, similarity matrix generation, and dendrogram construction for $16 \mathrm{~S}$ rRNA data was written in Microsoft QuickBASIC for use on IBM PC-AT and compatible computers. RNA sequences were entered and aligned as previously described (28). Similarity matrices were constructed from the aligned sequences by using only those sequence positions for which $90 \%$ of the strains had data. The similarity matrices were corrected for multiple base changes by the method of Jukes and Cantor (18). Phylogenetic trees were constructed by the neighbor-joining method (32).

GenBank accession numbers. GenBank accession numbers for organisms examined in this report are given in Table 1. Strains not previously recorded are $H$. acinonyx, $H$. pylori (ATCC $43504^{\mathrm{T}}$ ), " $F$. rappini," Wolinella succinogenes (ATCC 29543 ${ }^{\mathrm{T}}$ ), Campylobacter coli (CCUG 11283 ${ }^{\mathrm{T}}$ ), Campylobacter concisus (ATCC $33237^{\mathrm{T}}$ ), Campylobacter curvus (ATCC 35224 $4^{\mathrm{T}}$ ), Campylobacter jejuni (CCUG 112844), Campylobacter lari (CCUG 23947 ${ }^{\mathrm{T}}$ ), Campylobacter rectus (ATCC $33238^{\mathrm{T}}$ ), Campylobacter sputorum subsp. bubulus (ATCC 33491), a Campylobacter sp. (pig isolate, 40-6AT), [Bacteroides] gracilis (ATCC 33236 ${ }^{\mathrm{T}}$ ), and [Bacteroides] ureolyticus (ATCC $33387^{\mathrm{T}}$ ).

\section{RESULTS AND DISCUSSION}

Morphologic, ultrastructural, and growth characteristics. $H$. acinonyx cells were short $(0.3$ by 1.5 to $2 \mu \mathrm{m})$, spiral, gram-negative rods. They possessed tufts of two to five monopolar sheathed flagella (Fig. 1). Cells were motile. No periplasmic fibers, as are seen in $H$. felis, $H$. muridarum, and "F. rappini," were observed. Spherical forms 2 to $4 \mu \mathrm{m}$ in diameter were observed in older cultures. $H$. acinonyx strains grew under microaerophilic conditions at $37^{\circ} \mathrm{C}$ but not at 25 or $42^{\circ} \mathrm{C}$. No growth was seen on blood agar plates under aerobic or anaerobic conditions. These strains did not grow on brucella agar plates containing $1.0 \%$ glycine or $1.5 \%$ $\mathrm{NaCl}$.

Biochemical characteristics. $H$. acinonyx strains produced oxidase, catalase, alkaline phosphatase, acid phosphatase, phosphohydrolase, urease, gamma-glutamyl transpeptidase, and arginine beta-naphthylamide aminopeptidase. Leucine and histidine beta-naphthylamides were weakly hydrolyzed. $H$. acinonyx did not hydrolyze hippurate or produce acid from glucose, mannitol, inositol, sorbitol, rhamnose, sucrose, melibiose, amygdalin, or arabinose. $\mathrm{H}_{2} \mathrm{~S}$ was not produced. Proline, pyroglutamic acid, tyrosine, alanine, phenylalanine, and glycine beta-naphthylamides were not hydrolyzed. Strains of $H$. acinonyx were sensitive to metronidazole and cephalothin and resistant to nalidixic acid (no zone of inhibition). In addition, they were sensitive to penicillin, ampicillin, nitrofurazone, erythromycin, gentamicin, chlortetracycline, and chloramphenicol. They were resistant to sulfamethoxazole with trimethoprim and to vancomycin. Comparison of the biochemical characteristics of $H$. acinony $x$ with those of related organisms is shown in Table 3. The essential phenotypic distinctions were in size, morphology, and $\mathrm{G}+\mathrm{C}$ content as well as $16 \mathrm{~S}$ rRNA sequence (see below).

Total bacterial protein profile. Laser densitometry scanning of SDS-polyacrylamide gels indicated more than $70 \%$ similarity between $H$. acinonyx and $H$. pylori (Fig. 2). In contrast, $H$. acinonyx is less than $60 \%$ similar to $H$. mustelae and less than $50 \%$ similar to $H$. felis. Strains of a porcine gastric campylobacter are even less similar. The porcine campylobacter will be described in a subsequent report.Pre- 


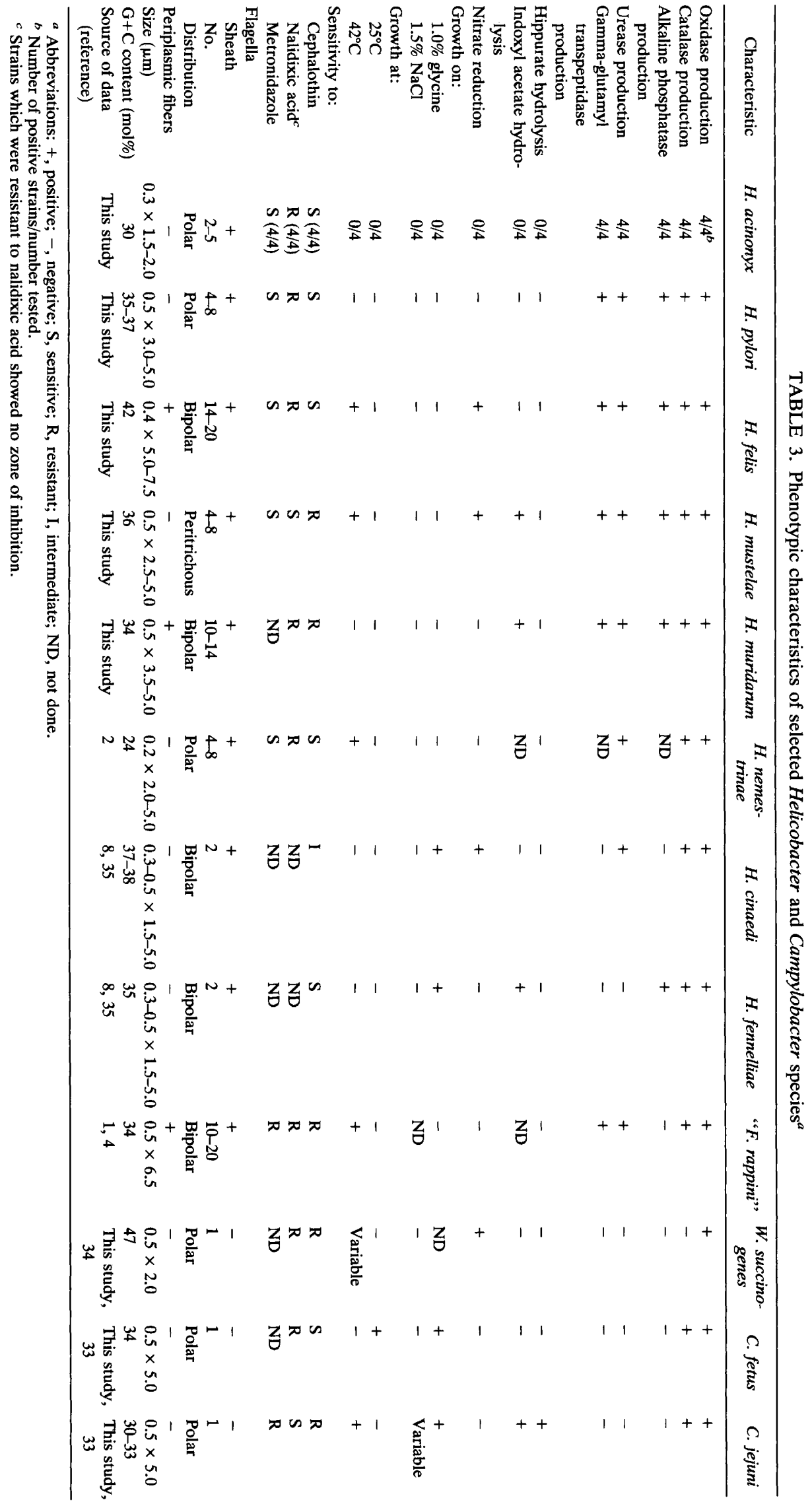




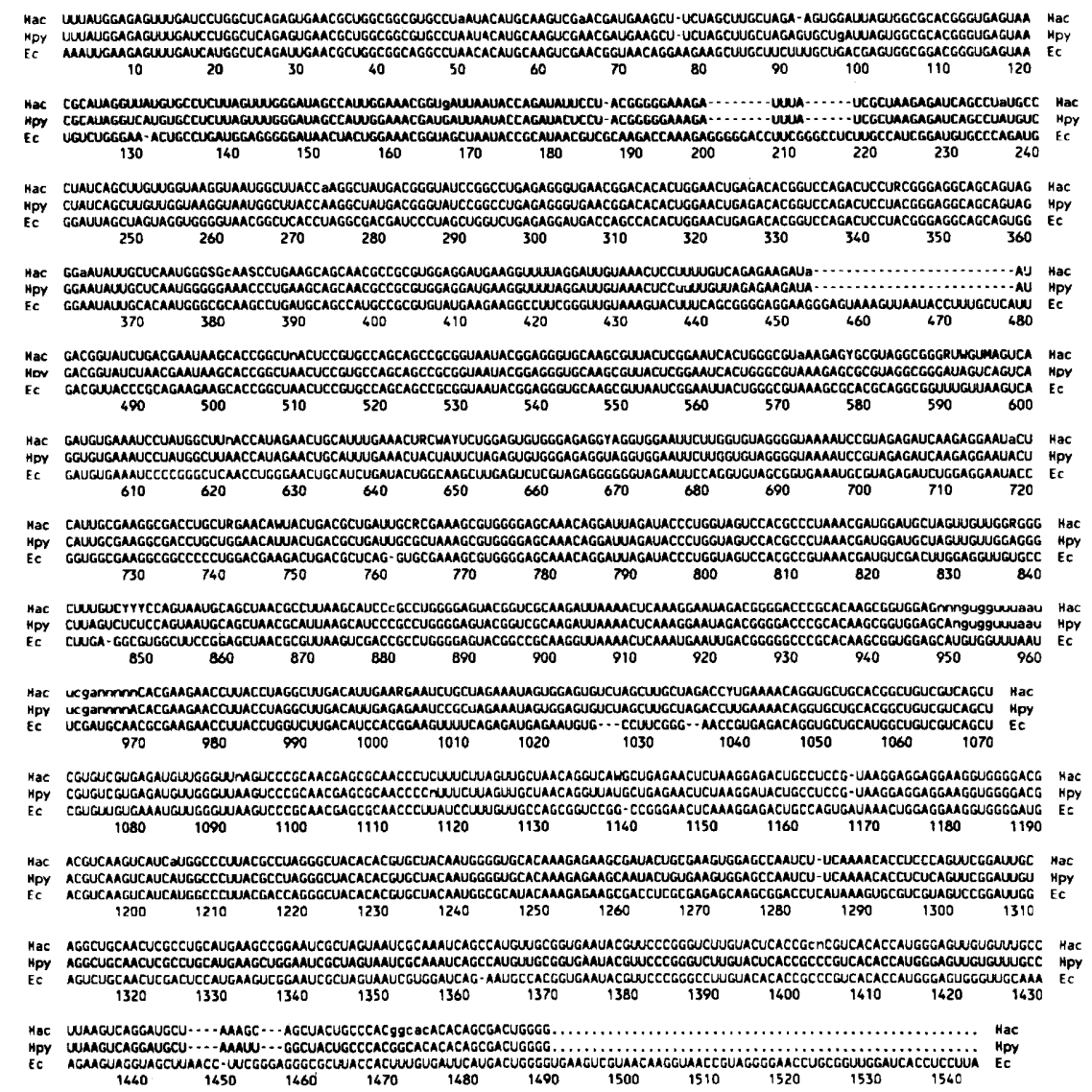

FIG. 3. Aligned 16S rRNA sequences for $H$. acinonyx 90-119 (Hac), $H$. pylori ATCC $43504^{\mathrm{T}}$ (Hpy), and $E$. coli (Ec). The numbering system is that of $E$. coli (3). The sequences are reported by using the International Union of Biochemistry single-letter code for nucleotide bases and ambiguities. Lowercase letters indicate some uncertainty in the base identity. Dashes indicate gaps inserted for alignment of sequences, and dots indicate regions that were not sequenced.

vious studies indicate that strains with $90 \%$ similarity are identical (26).

16S rRNA sequence. We determined approximately $95 \%$ of the total 16S rRNA sequence for strains $90-119$ and $90-1908$

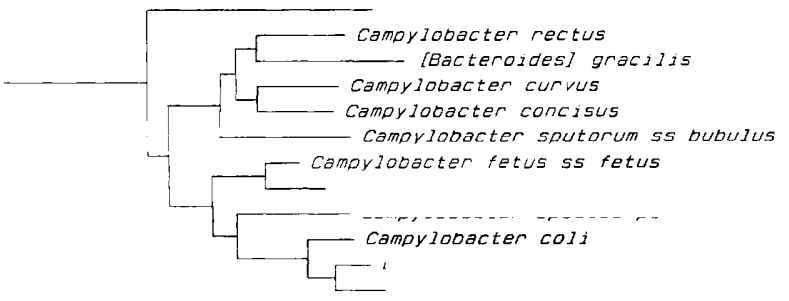

and for the reference strains listed in Table 1 . The sequences for the two cheetah isolates were identical. In Fig. 3, the $16 \mathrm{~S}$ rRNA sequence of strain 90-119 is aligned with sequences for $H$. pylori and $E$. coli. Sequences for the remaining reference strains are available for electronic retrieval from GenBank under the accession numbers given in Table 1. A detailed discussion of these reference sequences is the subject of a manuscript in preparation on the phylogeny of the genera Campylobacter and Helicobacter. A similarity matrix comparing $H$. acinonyx with 19 related species is given in Table 4. This matrix is based on sequence comparisons at 1,392 base positions. $H$. acinonyx is most closely related to $H$. pylori $(97.4 \%$ similarity) and the two $H$. felis strains (96.1 and $96.4 \%$ similarities). There are approximately 40 base differences between $H$. acinonyx and $H$. pylori 16S rRNA sequences which allow the design of DNA probes to easily differentiate these organisms. The probe 5'-CGTAGGAATATCTGGTATTAATCACCG-3' (E. coli positions 163 to 190 ) to $H$. acinonyx should not recognize $H$. pylori. $H$. acinonyx has four single-base signatures which differentiate it from other helicobacters: $C$ instead of $U$ at positions $239,1297,1336$, and 1453. A phylogenetic tree determined from the similarity data is shown in Fig. 4. $H$. acinonyx, $H$. pylori, and $H$. felis form a cluster that is separated from the other Helicobacter species (less than 94\% similarity). The two " $F$. rappini" strains examined are identical to one another and branch within the helicobacter 
TABLE 4. Similarity matrix based on 16S rRNA sequences ${ }^{a}$

\begin{tabular}{|c|c|c|c|c|c|c|c|c|c|c|c|c|c|c|c|c|c|c|c|c|}
\hline \multirow{2}{*}{ Organism } & \multicolumn{20}{|c|}{$\%$ Similarity and $\%$ difference compared with ${ }^{b}$ : } \\
\hline & $\mathrm{Ha}$ & $\mathrm{Hp}$ & Hf & $\mathrm{fD} \mathrm{HfC}$ & C Hms & $\mathrm{Hmr}$ & Fr & Ws & $\mathrm{Bu}$ & $\mathrm{Cr}$ & $\mathrm{Bg}$ & Ccr & Ccn & Cs & $\mathrm{Cf}$ & $\mathrm{Ch}$ & Csp & Cco & $\mathrm{Cj}$ & $\mathrm{Cl}$ \\
\hline $\mathrm{Ha}$ & $-\cdot$ & 97.4 & 96.1 & 196.4 & 93.4 & 92.4 & 92.4 & 90.4 & 83.9 & 83.6 & 83.0 & 84.8 & 84.7 & 85.2 & 84.6 & 83.8 & 83.4 & 84.5 & 84.8 & 84.6 \\
\hline Hp & 2.7 & $-\cdot$ & 95.3 & 395.4 & 93.8 & 93.0 & 93.1 & 90.7 & 84.1 & 84.1 & 83.9 & 85.2 & 85.1 & 85.7 & 85.2 & 84.6 & 84.1 & 84.9 & 85.2 & 85.1 \\
\hline HfD & 4.0 & 4.9 & - & 99.4 & 93.0 & 92.5 & 92.4 & 90.2 & 83.8 & 83.1 & 83.0 & 84.2 & 84.7 & 85.0 & 84.9 & 84.0 & 83.9 & 84.1 & 84.7 & 84.8 \\
\hline $\mathrm{HfC}$ & 3.6 & 4.7 & 0.6 & $6 \quad--$ & 93.4 & 92.6 & 92.6 & 90.1 & 83.6 & 83.1 & 82.9 & 84.2 & 84.6 & 85.1 & 184.8 & 83.8 & 83.7 & 84.1 & 84.6 & 84.8 \\
\hline Hms & 6.9 & 6.5 & 7.3 & 6.9 & $-\cdot$ & 95.7 & 95.8 & 93.7 & 85.7 & 84.9 & 84.4 & 85.8 & 86.0 & 87.4 & 86.0 & 85.6 & 85.3 & 86.0 & 86.5 & 86.7 \\
\hline Hmr & 8.0 & 7.3 & 7.9 & 7.8 & 4.4 & -- & 96.2 & 93.3 & 84.8 & 84.9 & 84.1 & 85.3 & 86.3 & 86.7 & 85.7 & 85.3 & 85.0 & 85.5 & 85.6 & 85.8 \\
\hline $\mathrm{Fr}$ & 8.0 & 7.3 & 8.0 & $\begin{array}{ll}0 & 7.8\end{array}$ & 4.3 & 3.9 & -- & 93.1 & 86.3 & 86.1 & 85.5 & 86.3 & 87.4 & 88.4 & 86.9 & 86.3 & 85.9 & 86.9 & 86.7 & 86.9 \\
\hline Ws & 10.3 & 9.9 & 10.5 & 510.6 & 6.6 & 7.0 & 7.2 & -- & 85.8 & 86.2 & 85.3 & 86.9 & 86.4 & 86.3 & 86.0 & 85.4 & 85.3 & 85.8 & 86.1 & 86.3 \\
\hline $\mathrm{Bu}$ & 18.2 & 17.8 & 18.3 & 318.5 & 15.8 & 16.9 & 15.1 & 15.7 & -- & 92.0 & 91.5 & 90.8 & 91.8 & 92.1 & 92.8 & 92.9 & 92.1 & 92.9 & 93.1 & 92.5 \\
\hline $\mathrm{Cr}$ & 18.5 & 17.9 & 19.1 & 19.1 & 16.9 & 16.8 & 15.3 & 15.2 & 8.5 & -- & 95.4 & 96.4 & 95.8 & 95.1 & 93.8 & 92.9 & 92.7 & 92.7 & 92.3 & 92.1 \\
\hline $\mathrm{Bg}$ & 19.3 & 18.1 & 19.2 & 219.4 & 17.5 & 17.9 & 16.1 & 16.4 & 9.1 & 4.8 & -- & 94.4 & 94.7 & 93.9 & 93.9 & 93.0 & 91.6 & 91.3 & 91.1 & 90.9 \\
\hline Cer & 16.9 & 16.5 & 17.8 & B 17.8 & 15.7 & 16.4 & 15.1 & 14.4 & 9.8 & 3.6 & 5.9 & - & 96.9 & 95.2 & 94.4 & 93.5 & 93.9 & 92.8 & 92.4 & 91.9 \\
\hline Ccn & 17.2 & 16.7 & 17.1 & 17.2 & 15.5 & 15.1 & 13.8 & 15.0 & 8.6 & 4.3 & 5.5 & 3.2 & -- & 95.1 & 95.5 & 94.5 & 93.9 & 93.8 & 93.4 & 93.6 \\
\hline $\mathrm{Cs}$ & 16.5 & 15.8 & 16.8 & 816.6 & 13.8 & 14.7 & 12.6 & 15.1 & 8.4 & 5.1 & 6.3 & 5.0 & 5.1 & $\cdots$ & 93.3 & 92.5 & 92.9 & 92.5 & 92.0 & 91.8 \\
\hline $\mathrm{Cf}$ & 17.2 & 16.4 & 16.8 & 817.0 & 15.5 & 15.8 & 14.3 & 15.4 & 7.6 & 6.5 & 6.3 & 5.8 & 4.6 & 7.0 & $\cdot-$ & 98.1 & 95.5 & 95.0 & 94.3 & 94.1 \\
\hline $\mathrm{Ch}$ & 18.2 & 17.2 & 18.0 & 18.2 & 15.9 & 16.4 & 15.1 & 16.3 & 7.5 & 7.5 & 7.3 & 6.8 & 5.7 & 7.9 & 1.9 & -- & 95.8 & 95.2 & 94.6 & 94.4 \\
\hline Csp & 18.8 & 17.8 & 18.1 & 18.4 & 16.3 & 16.7 & 15.6 & 16.4 & 8.4 & 7.6 & 8.9 & 6.4 & 6.4 & 7.5 & 4.6 & 4.3 & $\cdots$ & 95.7 & 95.0 & 94.6 \\
\hline Cco & 17.4 & 16.9 & 17.8 & 17.9 & 15.5 & 16.1 & 14.4 & 15.7 & 7.4 & 7.7 & 9.3 & 7.5 & 6.4 & 7.9 & 5.2 & 4.9 & 4.4 & - & 98.1 & 97.2 \\
\hline $\mathrm{Cj}$ & 17.0 & 16.5 & 17.2 & 17.2 & 14.8 & 16.0 & 14.6 & 15.4 & 7.2 & 8.1 & 9.4 & 8.0 & 6.9 & 8.4 & 5.9 & 5.6 & 5.1 & 1.9 & -- & 98.3 \\
\hline $\mathrm{Cl}$ & 17.2 & 16.7 & 16.9 & 17.0 & 14.6 & 15.8 & 14.4 & 15.2 & 7.9 & 8.4 & 9.7 & 8.6 & 6.7 & 8.7 & 6.2 & 5.9 & 5.6 & 2.8 & 1.7 & -- \\
\hline
\end{tabular}

a Abbreviations: Ha, H. acinonyx; Hp, H. pylori; HfD, H. felis DS3; HfC, H. felis CS1; Hms, H. mustelae; Hmr, H. muridarum; Fr, "F. rappini"; Ws, W. succinogenes; $\mathrm{Bu},[$ B.] ureolyticus; $\mathrm{Cr}, C$. rectus; $\mathrm{Bg},[B$.$] gracilis; Ccr, C. curvus; Ccn, C. concisus; Cs, C. sputorum; Cf, C. fetus; Ch, C. hyointestinalis; Csp,$ Campylobacter sp.; Cco, C. coli; $\mathrm{Cj}$, C. jejuni; $\mathrm{Cl}$, C. lari.

$b$ Numbers above the diagonal are uncorrected percentages of similarity. Numbers below the diagonal are percentages of difference corrected for multiple base changes by the method of Jukes and Cantor (18).

cluster. By 16S rRNA analysis, they appear to belong in the genus Helicobacter. Studies are in progress to determine whether strains described as " $F$. rappini" are members of a single, genetically homogeneous species. The spiral organism isolated by Philips and Lee from rodent intestinal mucosa was once considered an " $F$. rappini" strain (4) but is now recognized as $H$. muridarum (24). Previous arguments for excluding " $F$. rappini" from the genus Helicobacter (14) have been diluted by the inclusion of $H$. muridarum, which is morphologically identical to " $F$. rappini," and $H$. cinaedi, which, like " $F$. rappini," fails to produce alkaline phosphatase.

G+C content. The $\mathrm{G}+\mathrm{C}$ content of $H$. acinonyx was 29.9 $\pm 0.4 \mathrm{~mol} \%$. This value differentiates $H$. acinonyx from the other seven described Helicobacter species.

Description of $\boldsymbol{H}$. acinonyx sp. nov. Helicobacter acinonyx (acinonyx, L. gen. n. of the species Acinonyx jubilatus, from which it was isolated) is a short, spiral, gram-negative rod, 0.3 by 1.5 to $2.0 \mu \mathrm{m}$. Cells are motile and possess tufts of two to five sheathed monopolar flagella. No endospores are produced. Microaerophilic growth occurs at $37^{\circ} \mathrm{C}$ but not at 25 or $42^{\circ} \mathrm{C}$. Growth does not occur aerobically or anaerobically. Acid is not produced from glucose, mannitol, inositol, sorbitol, rhamnose, sucrose, melibiose, amygdalin, or arabinose. Oxidase, catalase, alkaline phosphatase, acid phosphatase, phosphohydrolase, urease, gamma-glutamyl transpeptidase, and arginine beta-napthylamide aminopepti- dase are produced. Proline, pyroglutamic acid, tyrosine, alanine, phenylalanine, and glycine beta-naphthylamide aminopeptidase are not detected. Hippurate and indoxyl acetate are not hydrolyzed. $\mathrm{H}_{2} \mathrm{~S}$ is not produced. Nitrate is not reduced. Growth does not occur in the presence of $1.0 \%$ glycine or $1.5 \% \mathrm{NaCl} . H$. acinonyx is resistant to nalidixic acid and sensitive to cephalothin and metronidazole. In addition, it is sensitive to penicillin, ampicillin, nitrofurazone, erythromycin, gentamicin, chlortetracycline, and chloramphenicol and resistant to sulfamethoxazole with trimethoprim and to vancomycin. $H$. acinonyx was isolated from the gastric mucosa of cheetahs. Four strains (90-119, 90-548, 90-736, and 90-1908) have been isolated and are available from The American Type Culture Collection (ATCC 51101, 51102, 51103, and 51104, respectively). The type strain, $90-119$, has a $\mathrm{G}+\mathrm{C}$ content of $30 \mathrm{~mol} \%$. It is deposited in the Culture Collection of the University of Göteborg, Göteborg, Sweden (CCUG 29263).

\section{ACKNOWLEDGMENTS}

This work was supported by Public Health Service grants DE04881 and DE-08303 from the National Institute of Dental Research, PHS grants DK-39570 and AI-07938 from NIH, and grants RR-01046 and RR-07036 from the National Center for Research Resources.

We thank Robert D. Leunk and Emma Williams for help in preparing the densitometry scans and Jane Schupp for technical help. 


\section{REFERENCES}

1. Archer, J. R., S. Romero, A. E. Ritchie, M. E. Hamacher, B. M. Steiner, J. H. Bryner, and R. F. Scheel. 1988. Characterization of an unclassified microaerophilic bacterium associated with gastroenteritis. J. Clin. Microbiol. 26:101-105.

2. Bronsdon, M. A., C. S. Goodwin, L. I. Sly, T. Chilvers, and F. D. Schoenknecht. 1991. Helicobacter nemestrinae sp. nov., a spiral bacterium found in the stomach of a pigtailed macaque (Macaca nemestrina). Int. J. Syst. Bacteriol. 41:148-153.

3. Brosius, J., M. L. Palmer, P. J. Kennedy, and H. F. Noller. 1978. Complete nucleotide sequence of a 16S ribosomal RNA gene from Escherichia coli. Proc. Natl. Acad. Sci. USA 75:48014808 .

4. Bryner, J. H. 1988. Flexispira rappini, gen. nov., sp. nov. A motile, urease-producing rod similar to Campylobacter pyloridis, p. 440-442. In B. Kaijser and E. Falsen (ed.), Proceedings of the Fourth International Workshop on Campylobacter Infections, Goteborg, Sweden. Goterna, Kungalv, Sweden.

5. Dewhirst, F. E., and B. J. Paster. 1992. Unpublished data.

6. Eaton, K. A., M. J. Radin, L. Kramer, R. Wack, R. Sherding, S. Krakowka, and D. R. Morgan. 1991. Gastric spiral bacilli in captive cheetahs. Scand. J. Gastroenterol. 26(Suppl. 181):3842.

7. Edwards, P. R., and W. H. Ewing. 1972. Identification of Enterobacteriaceae, 3rd ed. Burgess Publishing Co. Minneapolis.

8. Fennell, C. L., P. A. Totten, T. C. Quinn, D. L. Patton, K. K. Holmes, and W. E. Stamm. 1984. Characterization of campylobacter-like organisms isolated from homosexual men. J. Infect. Dis. 149:58-66.

9. Fox, J. G., E. B. Cabot, N. S. Taylor, and R. Laraway. 1988. Gastric colonization by Campylobacter pylori subsp. mustelae in ferrets. Infect. Immun. 56:2994-2996.

10. Fox, J. G., T. Chilvers, C. S. Goodwin, N. S. Taylor, P. Edmonds, L. I. Sly, and D. J. Brenner. 1989. Campylobacter mustelae, a new species resulting from the elevation of Campylobacter pylori subsp. mustelae to species status. Int. J. Syst. Bacteriol. 39:301-303.

11. Fox, J. G., P. Correa, N. S. Taylor, A. Lee, G. Otto, J. C. Murphy, and R. Rose. 1990. Helicobacter mustelae associated gastritis in ferrets: an animal model of Helicobacter pylori gastritis in humans. Gastroenterology 99:352-361.

12. Fox, J. G., A. Lee, G. Otto, N. S. Taylor, and J. C. Murphy. 1991. Helicobacter felis gastritis in gnotobiotic rats: an animal model of Helicobacter pylori gastritis. Infect. Immun. 59:785791.

13. Fox, J. G., B. J. Paster, F. E. Dewhirst, N. S. Taylor, L.-L. Yan, P. J. Macuch, and L. M. Chmura. 1992. Helicobacter mustelae isolation from feces of ferrets: evidence to support fecal-oral transmission of a gastric helicobacter. Infect. Immun. 60:606611.

14. Goodwin, C. S., J. A. Armstrong, T. Chilvers, M. Peters, M. D. Collins, L. Sly, W. McConnell, and W. E. S. Harper. 1989. Transfer of Campylobacter pylori and Campylobacter mustelae to Helicobacter pylori and Helicobacter mustelae comb. nov., respectively. Int. J. Syst. Bacteriol. 39:397-405.

15. Hodge, D. S., A. Borczyk, and L.-L. Wat. 1990. Evaluation of the indoxyl acetate hydrolysis test for differentiation of campylobacters. J. Clin. Microbiol. 28:1482-1483.

16. Hunble, M. W., A. King, and I. Phillips. 1977. API ZYM: a simple rapid system for the detection of bacterial enzymes. J. Clin. Pathol. 30:275-277.

17. Hwang, M.-N., and G. M. Ederer. 1975. Rapid hippurate hydrolysis method for presumptive identification of group B streptococci. J. Clin. Microbiol. 1:114-115.

18. Jukes, T. H., and C. R. Cantor. 1969. Evolution of protein molecules, p. 21-132. In H. N. Munro (ed.), Mammalian protein metabolism, vol. 3. Academic Press, Inc., New York.

19. Krakowka, S., D. R. Morgan, W. G. Kraft, and R. D. Leunk.
1987. Establishment of gastric Campylobacter pylori infection in the neonatal gnotobiotic piglet. Infect. Immun. 55:2789-2796.

20. Lane, D. J., B. Pace, G. J. Olsen, D. A. Stahl, M. L. Sogin, and N. R. Pace. 1985. Rapid determination of 16S ribosomal RNA sequences for phylogenetic analyses. Proc. Natl. Acad. Sci. USA 82:6955-6959.

21. Lee, A., J. G. Fox, G. Otto, and J. C. Murphy. 1990. A small animal model of human Helicobacter pylori active chronic gastritis. Gastroenterology 99:1315-1323.

22. Lee, A., S. L. Hazell, J. O'Rourke, and S. Kouprach. 1988. Isolation of a spiral-shaped bacterium from the cat stomach. Infect. Immun. 56:2843-2850.

23. Lee, A., S. Krakowka, J. G. Fox, G. Otto, and J. C. Murphy. 1992. Helicobacter felis as a cause of lymphoreticular hyperplasia in the dog stomach. Vet. Pathol., in press.

24. Lee, A., M. W. Phillips, J. L. O'Rourke, B. J. Paster, F. E. Dewhirst, G. J. Fraser, J. G. Fox, L. I. Sly, P. J. Romaniuk, T. J. Trust, and S. Kouprach. 1992. Helicobacter muridarum sp. nov., a microaerophilic helical bacterium with a novel ultrastructure isolated from the intestinal mucosa of rodents. Int. J. Syst. Bacteriol. 42:27-36.

25. Marshall, B. J., and J. R. Warren. 1984. Unidentified curved bacilli in the stomach of patients with gastritis and peptic ulceration. Lancet i:1311-1314.

26. Owen, R. J. M., S. L. W. On, L. R. Hill, A. D. Pearson, and D. R. Morgan. 1989. Strain variation in Campylobacter pylori detected by numerical analysis of one dimensional electrophoretic protein patterns. Antonie Leeuwenhoek 55:253-268.

27. Pace, B., E. A. Matthews, K. D. Johnson, C. R. Cantor, and N. R. Pace. 1982. Conserved 5S rRNA complement to tRNA is not required for protein synthesis. Proc. Natl. Acad. Sci. USA 79:36-40.

28. Paster, B. J., and F. E. Dewhirst. 1988. Phylogeny of campylobacters, wolinellas, Bacteroides gracilis, and Bacteroides ureolyticus by $16 \mathrm{~S}$ ribosomal ribonucleic acid sequencing. Int. J. Syst. Bacteriol. 38:56-62.

29. Paster, B. J., F. E. Dewhirst, C. Seymour, G. J. Fraser, and J. G. Fox. 1991. Helicobacter species isolated from bird and swine feces. Microbiol. Ecol. Health Dis. 4(Special issue):S107.

30. Paster, B. J., A. Lee, J. G. Fox, F. E. Dewhirst, L. A. Tordoff, G. J. Fraser, J. L. O'Rourke, N. S. Taylor, and R. Ferrero. 1991. Phylogeny of Helicobacter felis sp. nov., Helicobacter mustelae, and related bacteria. Int. J. Syst. Bacteriol. 41:31-38.

31. Radin, J. M., K. A. Eaton, S. Krakowka, D. R. Morgan, A. Lee, G. Otto, and J. G. Fox. 1990. Helicobacter pylori infection in gnotobiotic beagle dogs. Infect. Immun. 58:2606-2612.

32. Saitou, N., and M. Nei. 1987. The neighbor-joining method: a new method for reconstructing phylogenetic trees. Mol. Biol. Evol. 4:406-425.

33. Smibert, R. M. 1984. Genus Campylobacter, p. 111-118. In N. R. Krieg and J. G. Holt (ed.), Bergey's manual of systematic bacteriology, vol. 1. Williams \& Wilkins, Baltimore.

34. Tanner, A. C. R., and S. S. Socransky. 1984. Genus Wolinella, p. 646-650. In N. R. Krieg and J. G. Holt (ed.), Bergey's manual of systematic bacteriology, vol. 1. Williams \& Wilkins, Baltimore.

35. Totten, P. A., C. L. Fennell, F. C. Tenover, J. M. Wezenberg, P. L. Perine, W. E. Stamm, and K. K. Holmes. 1985. Campylobacter cinaedi (sp. nov.) and Campylobacter fennelliae (sp. nov.): two new campylobacter species associated with enteric disease in homosexual men. J. Infect. Dis. 151:131-139.

36. Vandamme, P., E. Falsen, R. Rossau, B. Hoste, P. Segers, R. Tytgat, and J. De Ley. 1991. Revision of Campylobacter, Helicobacter, and Wolinella taxonomy: emendation of generic descriptions and proposal of Arcobacter gen. nov. Int. J. Syst. Bacteriol. 41:88-103.

37. Westley, J. W., P. J. Anderson, V. A. Close, B. Halpern, and E. M. Lederberg. 1967. Aminopeptidase profiles of various bacteria. Appl. Microbiol. 15:822-825. 